\title{
Erratum to: Mechanisms controlling germline cyst breakdown and primordial follicle formation
}

\author{
Chao Wang ${ }^{1} \cdot$ Bo Zhou $^{1} \cdot$ Guoliang Xia $^{1}$
}

Published online: 18 March 2017

(C) Springer International Publishing 2017

\section{Erratum to: Cell. Mol. Life Sci. \\ DOI 10.1007/s00018-017-2480-6}

In the original publication, Acknowledgement section was missed to include by the authors. The missing information is given here.

\begin{abstract}
Acknowledgements This work was supported by the National Basic Research Program of China (973 Programs: 2013CB945501; 2014CB943202; 2014CB138503), National Natural Science Foundation of China (31371448; 31571540), Chinese Universities Scientific Fund (2015QC018) and Project for Young Scientists of State Key Laboratory of Agrobiotechnology (2015SKLAB4-1).
\end{abstract}

The online version of the original article can be found under doi:10.1007/s00018-017-2480-6.

Guoliang Xia

glxiachina@sohu.com; glxia@cau.edu.cn

1 State Key Laboratory for Agro-Biotechnology, College of Biological Science, China Agricultural University, Beijing 100193, China 